\title{
TRENDS IN MALE CONTRACEPTION
}

\author{
Fábio Firmbach Pasqualotto, Antônio Marmo Lucon, Eleonora Bedin Pasqualotto \\ and Sami Arap
}

PASQUAlOTTO FF et al. - Trends in male contraception. Rev. Hosp. Clín. Fac. Med. S. Paulo 58(5):275-283, 2003.

Methods that are available for male contraception, namely coitus interruptus, condoms, and vasectomy, have been used since the $19^{\text {th }}$ century. With the exceptions of a few improvements of these methods, no major progress has been made with respect to introducing new male contraceptives since then. It is extremely urgent to develop new, safe, effective, and reversible male contraceptive methods. Among all male contraceptive methods that are being investigated, the hormonal approach is the closest to clinical application. Hormonal contraception provides pregnancy protection by means of spermatogenic suppression. Androgen-progestin regimens currently represent the best available hormonal combination for induction of a profound suppression of spermatogenesis. Further development of new steroids is mandatory for increasing the choices of available contraceptive formulations and to optimize long-term safety of these regimens.

DESCRIPTORS: Testosterone. Androgen. Hormones. Contraception. Sterile.

During recent decades, the most important trends in family planning services have been improvement in the quality of care, reaching out to new population groups such as men and adolescents, and integrating family planning services into other reproductive health services ${ }^{1}$.

A number of methods aimed at the suppression of sperm production, the inhibition of sperm motility, or the prevention of sperm transport are under development ${ }^{2,3}$. However, new contraceptive methods are still not available for the male. The reasons for this are numerous, including insufficient research funding, lack of interest by both the scientific community and pharmaceutical companies, fear of side effects, and doubts regarding acceptability, as well as those inherent in the difficulty of the task. Of these obstacles, at least the doubts as to acceptability seem to be unfounded, since recent surveys show that well over $50 \%$ of men would use "the pill" if it were available $^{2,3}$. Of all the different contraceptive strategies tested for the male, the hormonal methods come closest to the ideal (Table 1) ${ }^{4}$. Considerable progress recently has been made in this field, in particular with the multicenter contraceptive efficacy trials of the World Health Organization. 5,6 These studies have established the feasibility of hormonal male contraception and have clearly identified the problems that still remain before such a method is ready for wider use. The awakening of interest of the pharmaceutical industry in the development of male hormonal contraceptives is an

From the Urology Department and Andrology Group, Hospital das Clínicas, Faculty of Medicine, University of São Paulo - São Paulo, Brazil.

Received for publication on April 24, 2003. encouraging sign, and the first "male pill" might be available in a few years.

\section{Nonhormonal methods}

Extracts of the Chinese medicinal plant Tripterygium wilfordii have been shown to contain compounds that cause infertility in male rats. One of them, triptolide, appears to be effective in reducing epididymal sperm concentration and in inducing an almost complete loss of sperm motility ${ }^{7}$. These characteristics make it an attractive lead as it is a substance that would induce infertility without suppressing spermatogenesis, would act quickly, and would be easily reversible ${ }^{8}$.

Further, several chemical compounds including a-chlorohydrin, 6chloro-6-deoxy sugars, gossypol, and triptolide have been shown to inhibit either spermatogenesis or epididymal sperm maturation ${ }^{9}$; however, their severe side effects, such as hypokalemia, 
Table 1 - Requirements of an ideal male contraceptive method.

As effective as comparable female methods

Acceptable to both partners

Rapidly effective

Free of side effects and especially without influence on masculinity, libido, and potency

Without influence on progeny

Reversible with regard to fertility

Easily available and financially affordable

neurotoxicity, immunosuppression, and irreversibility of azoospermia, preclude them from use in humans.

The strategies of nonhormonal male contraception relate to the pharmacological inhibition of testicular sperm production, in particular meiosis, and disruption of sperm maturation in the epididymis.

Our knowledge of the molecular and cell biology of spermatogenesis and sperm maturation has increased greatly. Findings regarding reproductive failures are often made in transgenic and knockout mice. It is possible that these studies will identify single genes that are critical in the production of fertile sperm. If such a gene codes for, for instance, a testis or germ cell-specific enzyme, receptor, or ion channel, specific blockage of its function by pharmacological means could be feasible. Such findings would provide concepts for the development of specific nonhormonal male contraceptives. Unfortunately, despite its clear potential, such a method must await future development ${ }^{9,10}$.

\section{Immunological methods}

Clinical observations have suggested that the presence of antisperm antibodies might be a cause of infertility and might also explain the low pregnancy rate observed after vasectomy reversal ${ }^{11}$. Since the presence of antisperm antibodies is not associated with any side effects other than infertility, the option of developing an antisperm vaccine seems possible. However, to date the difficulty in this approach has been the identification of an appropriate antigen and the avoidance of possible irreversible effects in the testis. Other approaches based on anti-FSH (follicle-stimulating hormone), anti-FSH receptor or anti-GnRH are being investigated as possible inhibitors of gametogenesis.

\section{Improved methods for male sterilization}

Vasectomy is easy to perform and has fewer associated complications compared to female sterilization, but the need for a skin incision, and the lack of assured reversibility appear to be the main issues limiting its acceptability. Two major techniques have been developed to overcome these problems: the no-scalpel method of vasectomy, which is gaining in popularity, and the percutaneous nonsurgical vas occlusion technique ${ }^{12}$. Occlusion techniques based on polyurethane or methylcyanoacrylate have been shown to have high local toxicity, with local reaction and occlusion on either side of the plug. Methods using silicone are under evaluation ${ }^{13}$. A new approach to nonsurgical vas occlusion under study involves an injection into the vas deferens of a preparation of styrene maleic anhydride dissolved in dimethyl sulfoxide. In monkeys, this approach has been shown to be reversible using a combination of palpation and percutaneous electrical stimulation ${ }^{14}$.

\section{Non-latex male condoms}

Advantages of non-latex condoms over latex condoms are that they are loose-fitting except at the base of the penis, are stronger in vitro, do not deteriorate in storage, are not affected by oil-based lubricants, and can be used by individuals who are allergic to latex. Polyurethane condoms as Avanti ${ }^{\circledR}$ and styrene-based plastic condoms such as Tactylon ${ }^{\circledR 15}$ are already on the market, and others are under development. Clinical trials with Avanti ${ }^{16}$ suggest that it may have higher slippage and breakage rates than the male latex condom; however, its acceptability is generally greater. The cost of these devices is likely to remain an obstacle to their widespread use in national family planning programs.

\section{Principles of hormonal male contraception}

The purpose of hormonal male contraception is to alter the endocrine environment of the body in such a way that the hormonal control of spermatogenesis is blocked. Spermatogenesis requires the stimulatory action of the two pituitary gonadotropins, luteinizing hormone (LH) and follicle-stimulating hormone (FSH). The role of $\mathrm{LH}$ is to stimulate Leydig cell testosterone production and to maintain the very high intratesticular testosterone concentration (100-fold compared to peripheral circulation) that is needed for spermatogenesis. The role of FSH is less clear, but it seems to be important for the maintenance of qualitatively normal spermatogenesis by stimulating the recruitment of spermatogonia into the spermatogenic maturation process. Hence, the effective suppression of gonadotropins, in particular that of the LH/testosterone link, can be expected to inhibit spermatogenesis. Although FSH action is also involved in spermatogenesis, the selective inhibition of FSH is not enough to inhibit it, as has been demonstrated recently in mice with disrupted function 
(knockout) of the FSH b-subunit and FSH receptor genes ${ }^{17-19}$ and in men with an inactivating mutation in the FSH receptor gene ${ }^{20}$. This finding casts doubts on the efficacy of male contraceptive strategies involving the inhibition of FSH action or the manipulation of inhibin levels.

The elimination of testicular testosterone production by gonadotropin suppression also suppresses the extragonadal levels of androgens, thereby abolishing their anabolic effects on potency and libido. To avoid this, physiologically low levels of peripheral testosterone have to be maintained by androgen supplementation. The physiological testosterone levels needed are so low that they do not reinitiate spermatogenesis - as stated before, the normal intratesticular testosterone concentration is 100 -fold higher than that found in the peripheral circulation.

Gonadotropin suppression can be achieved by a variety of hormonal regimens (Table 2). An ideal alternative is testosterone itself, since it has the ad-

Table 2 - The various strategies for hormonal male contraception.

\footnotetext{
1. Testosterone alone testosterone enanthate in oil testosterone pellets testosterone microspheres

2. New parenteral testosterone preparations testosterone buciclate testosterone undecanoate

3. Testosterone or progestins

4. Testosterone and antiandrogens

5. Testosterone and estrogens

6. Testosterone and GnRH analogs

7. Other androgens

19-nortestosterone

$7 \alpha$-methyl-19-nortestosterone (MENT)

$5 \alpha$-dihydrotestosterone

8. Immunizations

against FSH or FSH receptor against $\mathrm{GnRH}$ or $\mathrm{GnRH}$ receptor
}

vantage that the same compound produces both gonadotropin suppression and the supplementation of peripheral androgen levels. If the dose given slightly exceeds the physiological maintenance dose, gonadotropin and testicular testosterone production are blocked, but peripheral testosterone levels are preserved to maintain the physiological extragonadal action of the androgens. The other practically feasible antigonadotropin agents include progestins and gonadotropin releasing hormone ( $\mathrm{GnRH})$ analogs. Since these hormones only provide the gonadotropin suppression, androgen supplementation must be included in the regimen to maintain the extragonadal activity of the androgens.

\section{Feasibility of hormonal male contraception: the WHO multicenter trials}

Clinical trials testing the suppression spermatogenesis by androgen treatment have been conducted since the late 1970s. A common feature of these trials is that about two-thirds of the men involved, usually of Caucasian origin, display reversible suppression of spermatogenesis to the point of azoospermia, while variable suppression is observed in the rest, usually to the point of severe oligozoospermia. The first World Health Organization (WHO) multicenter study showed that the azoospermia achieved in this fashion, using a standard regimen of 200 mg testosterone enanthate (TE) per week intramuscularly, resulted in effective contraception ${ }^{5}$. The men participating developed azoospermia, used no other form of contraception for 12 months, and among the 137 couples involved, only 1 pregnancy occurred. The compliance of the men was good, the side effects were tolerable, and in all cases the antispermatogenic effect was reversible. An interesting feature was that the rate of azoospermia was much greater in men of Asian origin than among Caucasians (91\% vs. 60\%).

The second phase of the WHO study consisted of an investigation into the extent to which the fertility of men displaying severe oligozoospermia may be affected ${ }^{6}$. Using a similar study protocol, men with oligozoospermia below $3 \times 10 \% \mathrm{~mL}$ were allowed to begin a 12-month use of testosterone. Altogether, of the 349 men entering study, $77 \%$ remained consistently azoospermic, $10 \%$ were consistently oligozoospermic but never azoospermic, and $13 \%$ fluctuated between oligozoospermia and azoospermia. Only $2.2 \%$ failed to achieve the required azoospermia or oligozoospermia $\left(<3.0 \times 10^{6} / \mathrm{mL}\right)$. No pregnancies occurred amongst the azoospermic men, but in those with oligozoospermia, pregnancies occurred at a rate of 8.1 per 100 persons/year. The likelihood of contraceptive failure was directly related to the remaining sperm count.

The combined efficacy rate of the $200 \mathrm{mg} /$ week testosterone enanthate (TE) method is similar to those of hormonal female methods but superior to the reversible male methods (condoms, withdrawal, periodic abstinence). The risk of pregnancy is almost exclusively in the oligozoospermic group. Whether this rate of contraceptive efficacy is enough or whether only $100 \%$ azoospermic can be accepted is a matter of debate. It may be feasible to state that, on the basis of these findings, azoospermia should be set as a goal for future developmental work on this method.

It is evident that weekly testosterone injections, as used in the WHO trials, are not practical means of male contraception and have served primarily to prove that the principle works. Once a method with satisfactory contraceptive efficacy has been developed, the challenge of developing a more practical means of administration 
of the hormone treatment can be transferred to pharmaceutical companies.

\section{The strategies of hormonal male contraception}

\section{Testosterone alone}

In most of the earlier male hormonal contraceptive trials, including those of the $\mathrm{WHO}^{5,6}$, the androgen preparation used has been TE by intramuscular administration. In many respects, this regimen is suboptimal in terms of pharmacokinetics for contraceptive purposes. The plasma androgen levels achieved immediately after the injection are too high and display considerable variation at different times in relation to the injection. This may be the reason for the side effects reported. A weekly $200 \mathrm{mg}$ TE dose has been found optimal for contraception, but for the above reasons it is considered unsatisfactory for wider use.

A more prolonged and steady effect can be achieved with testosterone implants that last for 4 to 6 months $^{21,22}$ and biodegradable spheres lasting for 2-3 months ${ }^{23}$. An optimal preparation is considered to be an injectable depot that would provide constant release of the steroid for several months. A very promising compound in this respect is testosterone buciclate (TB), synthesized under the auspices of the WHO. It has a long effective phase of 3-4 months after a single injection. A dose of $1200 \mathrm{mg}$ of the compound in a contraceptive trial on spermatogenic suppression was shown to be comparable to a weekly injection of $\mathrm{TE}^{24}$. Another promising preparation is injectable testosterone undecanoate, which has been given every 6 weeks in recent successful contraceptive trials ${ }^{25,26}$, and it is possible that even a less frequent interval of treatment would be attainable with this compound.

One problem with testosterone is the relatively weak androgenic potency of this molecule. Since the amount administered has to be at least equal to the daily production rate of testosterone, i.e. 3-10 mg, the limited solubility of testosterone esters in the oil vehicles used for intramuscular injection calls for large injection volumes. Therefore, more potent androgenic molecules would be desirable. Since the severity of the side effects of a drug is often related to its molar dose, more potent androgens might also mean reduced side effects. Even more potent androgens exist, and in the future they might be able to replace the compounds currently undergoing testing.

\section{Testosterone in combination with some other gonadotropin- suppressing agent}

\section{Testosterone plus progestin}

The advantage of testosterone is that the same molecules provide both suppression of gonadotropins and supplementation of peripheral androgen levels. However, several potential advantages, including faster suppression of spermatogenesis, increased efficacy, reduction of the androgen load, and potential by fewer side effects, can be seen if the testosterone is used in combination with some other agent inhibiting gonadotropin secretion. These potential advantages still await practical demonstration.

Recent studies have shown that a combination of a suboptimal dose of testosterone, either $100 \mathrm{mg}$ TE/week intramuscularly plus levonorgestrel $500 \mathrm{mg} /$ day orally ${ }^{27}$, or 4 testosterone pellets ( $800 \mathrm{mg}, 6 \mathrm{mg} /$ day) plus 300 $\mathrm{mg}$ depot medroxyprogesterone acetate $^{28}$, were more effective than testosterone alone in suppressing spermatogenesis. However, the overall effect was comparable to that of the WHO studies with the TE dose $(200 \mathrm{mg}$ / week) that was optimal for contraceptive efficacy, and it remains open as to whether improved contraceptive efficacy can be achieved with the andro- gen/progestin combination. This possibility is likely in the light of the latest studies using a combination of testosterone and a variety of progestins (dimedroxyprogesterone 75 acetate, desogestrel, and levonorgestrel $)^{29}$.

It also remains to be seen whether the potential advantage of reducing the androgen load and its side effects will in fact materialize. Although progestins effectively suppress gonadotropin secretion, we do not know whether the hormone combination works in an additive or synergistic fashion. The latter mechanism could be the key to achieving uniform azoospermia in all men treated, as well as to reducing the steroid load. Progestins also have direct inhibitory effects on Leydig cell steroidogenesis ${ }^{30}$ and 5a-reductase activity ${ }^{31}$, which may further increase the antispermatogenic effect. On the negative side, progestins may have untoward effects on highdensity lipoprotein (HDL) cholesterol $^{27}$, and the worst possible scenario would be that gains in increased efficacy were achieved at the expense of increased side effects. To minimize the side effects, the androgen component of the treatment should mimic the endogenous plasma androgen levels as closely as possible, while the additional antigonadotropic substance should block gonadotropin secretion as effectively as possible.

\section{Testosterone plus antiandrogen}

Another alternative is the use of cyproterone acetate (CPA), which is both an antiandrogen and antigonadotropic factor, due to its progestational effect. Cyproterone acetate clearly enhances the antispermatogenic effect of a submaximal dose of TE $(100 \mathrm{mg} / \text { week })^{32}$, but it remains unknown whether the combinations of CPA + TE offer any advantage over a maximally effective dose of TE alone. In theory, its main systemic effect could be antigonadotropic in synergy 
with testosterone, and in the testes it could additionally be antiandrogenic, thereby eliminating the action of the residual androgen levels.

\section{Testosterone plus GnRH analogs}

The gonadotropin releasing hormone $(\mathrm{GnRH})$ agonists and antagonists are a very promising group of compounds for combination with testosterone, especially due to their specific suppressive effects on gonadotropins and their very few side effects. The GnRH agonists have paradoxical antigonadotropic effects through the down-regulation of the GnRH signal transduction system. The antagonists function as competitive inhibitors of endogenous GnRH action.

The GnRH agonists used alone effectively suppress serum testosterone to the castration range in prostatic cancer patients, which brings about effective suppression of spermatogenesis ${ }^{33}$. Paradoxically, additional testosterone supplementation in contraceptive trials attenuates the suppressive effect of GnRH agonists on spermatogenesis. In 12 clinical trials with various $\mathrm{GnRH}$ agonists, azoospermia was achieved in only 24 out of 106 subjects $(23 \%)$. The reason for this failure remains unknown, but it is conceivable that the recovery of FSH secretion during the treatment ${ }^{34}$, together with the low remaining intratesticular testosterone, could reinitiate spermatogenesis. Therefore, the GnRH agonists have been abandoned for further development as male contraceptives.

The combination of testosterone with GnRH antagonists for male contraception has proven much more promising. The azoospermic effect seems to be especially profound if the testosterone supplementation is delayed and the dose is low. Since higher doses of testosterone supplementation reduce the contraceptive efficacy, the marginally increased intratesticular testosterone level, perhaps with re- sidual gonadotropic activity, appears critical in such failures.

The GnRH antagonists have practically no side effects other than skin reactions with some compounds due to the release of histamine. At present, they do not constitute a viable alternative for male contraception because of their high cost, difficulty of administration, low potency, and local irritation caused.

\section{Epididymal approaches to male contraception}

The advantage of post-testicular contraception lies in the rapid onset of infertility, its reversible nature, and the rapid return to fertility once the therapy is discontinued. Therefore, post-testicular contraception has much more to offer than the hormonal approaches that block testicular sperm production and take months to reduce spermatozoa concentration sufficiently for effective contraception. Although epididymal malfunction has been suggested to account for $20 \%$ of all the cases of human necrozoospermia, there are a undoubtedly few cases of male infertility caused by epididymal dysfunction $^{35}$. Since there is increasing evidence that human spermatozoa within the epididymal canal undergo a similar maturational process to that of the sperm of other species, post-testicular contraceptives for animals based on physiological principle of sperm transport, maturation, and storage are applicable to man.

Those approaches involving arrest of contraction at ejaculation could be close to clinical testing, since autonomic drugs are known, have been tested, and should shortly be available, with only small developments in timing and modes of delivery being required $^{36-39}$. Altering the composition of epididymal fluid for contraceptive purpose does not currently seem promising because of the lack of organ specificity of the synthetic, secretory, and transport process in the epididymis, although immunological sequestration of epididymal proteins is being seriously considered for humans. Specific epididymal transporters need to be better identified before drugs that make changes in the fluid composition can be tested. Selective inhibition of sperm glycolysis is the most successful approach in animals and could be effective in man.

\section{Remaining problems in the development of a hormonal male contraceptive}

As stated above, the maximal suppression of the intratesticular androgen level is the key to hormonal suppression of spermatogenesis and is simple in principle. A high enough dose of testosterone, alone or in combination with another antigonadotropic agent, should suppress gonadotropin secretion to such a low level that the Leydig cell function is blocked. However, as experience shows, there seems to be a fine balance between success and failure. If the antigonadotropic dose is too low, the desired suppression of intratesticular testosterone is not achieved. If the androgen component of the treatment is too high, it may have stimulatory effects on spermatogenesis. Moreover, the doses of single or multiple compounds used must guarantee maximal efficiency with minimal side effects. The studies so far performed have shown convincingly that hormonal male contraception is possible. However, 3 main problems remain: lack of uniform suppression to the point of azoospermia, the mode of hormone administration, and potential short-term and long-term side effects.

\section{The lack of uniform suppression to the point of azoospermia}

There is still no clear-cut answer as 
to why all men, especially those of Caucasian origin, should not respond to the treatment and attain azoospermia. WHO scientists have assessed the anthropometric, seminal, hormonal, and biochemical data before, during, and after TE treatment as potential predictors of inconsistent azoosper$\mathrm{mia}^{40,41}$. The only significant findings were that the azoospermic men had faster rates of the decline and recovery of spermatogenesis, higher pretreatment FSH levels, and longer-term rebound of gonadotropins after treatment. No differences were found in the pharmacodynamics of TE as between the 2 groups $^{42}$. One study showed that the responder had significantly lower levels of sex-hormone-binding globulin (SHBG) throughout the whole treatment and lower LH and testosterone levels at the baseline. In addition, another study reports higher 5a-reductase activity of the non-responders during the TE therapy, which could indicate that the suppression of bioactive androgen levels may be less profound in these men than in those achieving azoospermia ${ }^{43}$.

No clear-cut reasons for nonuniform azoospermia can be identified from the existing observations. They give the impression that there is a subtle difference in hormonal equilibrium and set point of the feedback mechanisms for gonadotropins and androgen dependence of spermatogenesis between the 2 groups of men. It may also be that spermatogenesis in the poor responders is less closely dependent on androgens, or that their intratesticular androgen production has a higher gonadotropin-independent component, either autonomously or through paracrine stimulation. It may also be possible that some other blood-borne factors may be able to maintain their testicular steroidogenesis. The variable testicular physiology may be caused by genetic polymorphism, reflecting borderline functional alterations in the key gene(s) regulating spermatogenesis. It is even possible that the LH or FSH receptors of these men have polymorphisms allowing higher than normal constitutive, non-ligand-dependent signal transduction.

A genetic cause for the variable spermatogenetic response is strongly suggested by the ethnic differences observed $^{44}$. When Caucasian and Asian (mostly Chinese) men were compared, the rates of spermatogenic suppression to the point of azoospermia were $66.7 \%$ and $89.2 \%$, respectively. However, when the rates of suppression to the point of azoospermia and/or below 3 million $/ \mathrm{mL}$ were compared, the respective figures were $95.6 \%$ and $98.4 \%$ (thus, the ethnic difference almost disappeared). Hence, the difference is seen only at the lower end of the response, from severe oligozoospermia to complete azoospermia.

\section{The mode of hormone administration}

An optimal means for hormone administration has not yet been identified. It is clear that a long-acting depot preparation would be the most desirable method. Whether the active androgen should be testosterone or a synthetic androgen needs also to be determined. The testosterone molecule has characteristically a relatively low rate of side effects. However, its low intrinsic androgen activity makes it technically difficult to use in the development of a depot preparation, since rather high doses of steroids are needed. Likewise, it is still an open question as to whether combining androgen with another antigonadotropic compound is really advantageous, because no convincing data on increased efficiency or less intense side effects have been presented. Nevertheless, probably, once the problem of lack of uniform suppression to the point of azoospermia is solved, the develop- ment of a suitable pharmaceutical androgen preparation for wide use is a less demanding technical challenge. Very promising results have very recently been obtained with a combination of progestin with slow-release injectable testosterone esters. The optimal preparation that may be within our reach on the basis of today's knowledge could thus be a subcutaneous progestin/androgen implant.

\section{Potential short-term and long-term side effects}

Testosterone plays a major role in male sexual development. Exposure of females to testosterone in utero can induce masculine characteristics such as anovulation, increased anogenital distance, absence of nipples, retention of male-like tissues, and agenesis of the lower vagina. In addition, high levels of androgens during fetal development can lead to toxic effects such as reduced litter size and viability. However, there is no data regarding these possible side effects in case of a pregnancy involving men taking oral contraceptives ${ }^{45}$.

Because healthy men will be receiving the hormonal contraceptive, strict safety margins are required, and the potential short-term and long-term side effects of the therapy must be fully recognized. Concerning acute side effects, the most common medical reasons for discontinuation in the recent treatment trials have been acne (3\%) and changes of mood, behavior, and libido (4\%), while other idiosyncratic or incidental conditions were uncommon $(<1 \%)^{46}$. With respect to metabolic effects, a small but significant decrease in HDL cholesterol (15-20\%), but not in other lipoproteins, is a consistent finding ${ }^{47-49}$. The significance of these findings remains uncertain. No sustained, marked prothrombotic effects of the treatment were found ${ }^{50}$.

From the above studies, it was con- 
cluded that the acute effects reflect the relatively high peak levels and fluctuation of plasma testosterone levels with the weekly TE injections, rather than an inherent feature of hormonal male contraception, highlighting the need for long-acting preparations of testosterone with more stable delivery kinetics. This is suggested by the lower frequency of the above side effects in men treated with testosterone implants that result in closer-to-normal physiological levels of plasma testosterone without compromising contraceptive efficacy ${ }^{21}$.

While the role of androgens in the progression of benign hyperplasia and carcinoma of the prostate is well documented, it is not known whether the lifetime exposure to androgens affects the morbidity of these diseases. At least theoretically, androgen therapy increases the risk of developing prostatic diseases. One study reported a slight, though significant, increase in prostatic size but no effect on prostate-specific antigen (PSA) $)^{51}$.

One concern has been the effect of androgens on behavior. In normal men, supraphysiological doses of testosterone may result in some degree of sexual arousal without stimulating sexual activity, but no increase in aggression has been scientifically documented $^{52,53}$. Serious physiological side effects of androgens are extremely rare, despite reports of such cases amongst anabolic steroid abusers. In these cases, anabolic steroid abuse is more likely to be the consequence than the cause of the mental instability reported $^{54}$. Due to the inevitable uncertainty of long-term adverse effects of this treatment, a good approach is to use treatments that mimic as closely as possible the physiological androgen production profile.

\section{FUTURE PERSPECTIVES}

In the short term, as outlined above, 3 main questions remain to be answered in the development of a male hormonal contraceptive. Once these questions have been solved, the first generation of hormonal male contraceptives could be ready for use. It is still difficult to predict how long it will take to find answers to these questions. This depends very much on the availability of research facilities, which depend on the interest of the lay public, health professionals, sociopolitical opinion leaders, and the pharmaceutical industry. If adequate resources for this work were to be made available soon, the task might be completed within the next 5 years.

\section{RESUMO}

PASQUALOTTO FF e col. - Tendências na contracepção masculina. Rev. Hosp. Clín. Fac. Med. S. Paulo 58(5):275-283, 2003.

Métodos disponíveis para contracepção como coito interrompido, preservativo e vasectomia são usados desde o século 19. Com exceção a alguma melhora nestes métodos, nenhum progresso maior tem sido feito com relação à introdução de novos contraceptivos masculinos desde então. É de extrema urgência o desenvolvimento de um novo método contraceptivo seguro, efetivo e reversível. Entre todos os métodos contraceptivos que estão sendo investigados, a abordagem hormonal é a que está mais perto para aplicação clínica. A contracepção hormonal fornece proteção contra a gravidez por meio da supressão na espermatogênese. Tratamentos que incluem andrógeno e progestágenos representam na atualida- de a melhor combinação hormonal disponível para induzir uma profunda supressão na espermatogênese. $\mathrm{O}$ desenvolvimento futuro de uma nova formulação esteróide é mandatório para melhorar as chances de formulações contraceptivas disponíveis e otimizar o efeito a longo-prazo de tais regimes.

DESCRITORES: Testosterona. Andrógeno. Hormônios. Contracepção. Estéril.

\section{REFERENCES}

1. RALEIGH VS - Trends in world population: how will the millennium compare with the past? Hum Reprod Update 1999; 5:500-505.

2. CUMMINGS DE, BREMMER JW - Prospects for new hormonal male contraceptives. Endocrin Metab Clin North Am 1994; 23:893-921.
3. MARTIN CW, ANDERSON RA, CHENG L et al. - Potential impact of hormonal male contraception: cross-cultural implications for development of novel preparations. Hum Reprod 2000; 15:637-45.

4. NIESCHLAG E, BEHRE HM, ENGELMANN U et al. - Male contribution to contraception. In: NIESCHLAG E, BEHRE H, eds. Andrology; Male Reproductive Health and Dysfunction. Heidelberg, Springer, 1997. p. 375-93. 
5. WHO Task Force on Methods for the Regulation of Male Fertility: Contraceptive efficacy of testosterone-induced azoospermia in normal men. Lancet 1990; 336:955-9.

6. WHO Task Force on Methods for the Regulation of Male Fertility: Contraceptive efficacy of testosterone-induced azoospermia and oligozoospermia in normal men. Fertil Steril 1996; 65: 821-90.

7. HIKIM AP, LUE YH, WANG C et al. - Post-testicular antifertility action of triptolide in the male rat: evidence for severe impairment of cauda epididymal sperm ultrastructure. J Androl $2000 ; 21: 431-7$.

8. LUE Y, SINHA HIKIM AP, WANG C et al. - Triptolide: a potential male contraceptive. J Androl 1998; 19:479-86.

9. FRAYNE J, HALL L - The potential use of sperm antigen as targets for immunocontraception: past, present and future. $\mathbf{J}$ Reprod Immunol 1999; 43:1-33.

10. NAZ RK - Fertilization-related sperm antigens and their immunocontraceptive potentials. Am J Reprod Immunol 2000; 44:41-6.

11. CARBONE DJ, SHAH A, THOMAS AJ et al. - Partial obstruction, not antisperm antibodies, causing infertility after vasovasostomy. J Urol 1998; 159:827-30.

12. LIU X, LI S. Vasal sterilization in China. Contraception 1993; 48:255-65.

13. CHEN Z, GU Y, LIANG X et al. - Morphological observations of vas deferens occlusion by the percutaneous injection of medical polyurethane. Contraception 1996; 53:275-79.

14. LOHIYA NK, MANIVANNAN B, MISHRA PK - Repeated vas occlusion and non-invasive reversal with styrene maleic anhydride for male contraception in lanur monkeys. Int $\mathbf{J}$ Androl 2000; 23:36-42.

15. CALLAHAN M, MAUCK C, TAYLOR D et al. - Comparative evaluation of three Tactylon ${ }^{\mathrm{TM}}$ condoms and a latex condom during vaginal intercourse: breakage and slippage. Contraception 2000; 61:205-15.

16. ROSEMBERG M, WAUGH MS, SOLOMON HM et al. - The male polyurethane condom: a review of current knowledge. Contraception 1996; 53:141-6.

17. KUMAR TR, WANG Y, LU N et al. - Follicle-stimulating hormone is required for ovarian follicle maturation but not male fertility. Nat Genet 1997; 15:201-4.

18. DIERICH A, SAIRAM MR, MONACO L et al. - Impairing folliclestimulating hormone (FSH) signaling in vivo: targeted disruption of the FSH receptor leads to aberrant gametogenesis and hormonal imbalance. Proc Natl Acad Sci USA 1998; 95: 13612-27.

19. ABEL MH, WOOTTON AN, WILKINS V et al. - The effect of a null mutation in the follicle-stimulating hormone receptor gene on mouse reproduction. Endocrinology 2000; 141:1795803.

20. TAPANAINEN JS, AITTOMAKI K, MIN J et al. - Men homozygous for an inactivating mutation of the folliclestimulating (FSH) receptor gene present variable suppression of spermatogenesis and fertility. Nat Genet 1997; 15:205-6.
21. HANDELSMAN DJ, CONWAY AJ, BOYLAN LM. - Suppression of human spermatogenesis by testosterone implants. J Clin Endocrinol Metab 1992; 75:1326-32.

22. HANDELSMAN DJ - Hormonal male contraception: progress and prospects for the $21^{\text {st }}$ century. Aust NZ J Med 1995; 25: 808-16.

23. BHASIN S, SWERDLOFF RS, STEINER B et al. - A biodegradable testosterone microcapsule formulation provides uniform eugonadal levels of testosterone for 10-11 weeks in hypogonadal men. J Clin Endocrinol Metab 1992; 74:7583.

24. BEHRE H, BAUS S, KLIESCH S et al. - Potential of testosterone buciclate for male contraception: endocrine differences between responders and non-responders. J Clin Endocrinol Metab 1995; 80:3394-403.

25. KAMISCHKE A, PLÖGER D, VENHERM S et al. - Intramuscular testosterone undecanoate with or without oral levonorgestrel: a randomized placebo-controlled feasibility study for male contraception. Clin Endocrinol 2000; 53:43-52.

26. KAMISCHKE A, VENHERN S, PLÖGER D et al. - Intramuscular testosterone undecanoate and norethisterone enanthate in a clinical trial for male contraception. J Clin Endocrinol Metab 2000; 86:303-9.

27. BEBB RA, ANAWALT BD, CHRISTENSEN RB et al. - Combined administration of levonorgestrel and testosterone induces more rapid and effective suppression of spermatogenesis than testosterone alone: a promising male contraceptive approach. J Clin Endocrinol Metab 1996; 81:757-62.

28. HANDELSMAN DJ, CONWAY AJ, HOWE CJ et al. - Establishing a minimum effective dose and additive effects of depot progestin in suppression of human spermatogenesis by a testosterone depot. J Clin Endocrinol Metab 1996; 81:411321.

29. OXYNOS C \& WU FC. - Male hormonal contraception. Ballière's Best Pract Clin Res Endocrinol Metab 2000; 14:473-87.

30. EL-HEFNAWY T, HUHTANIEMI I - Progesterone can participate in down-regulation of luteinizing hormone receptor gene expression and function in cultured murine Leydig cells. Mol Cell Endocrinol 1998, 137:127-38.

31. MAUVAIS-JARVIS P, KUTTEN P, BAUDOT N - Inhibition of testosterone conversion to dihydrotestosterone in men treated percutaneously by progesterone. J Clin Endocrinol Metab 1974; 38:142-7.

32. MERIGGIOLA MC, BREMNER WJ, PAULSEN CA et al. - A combined regimen of cyproterone acetate as a potentially highly effective male contraceptive. J Clin Endocrinol Metab 1996; 81:3018-23.

33. HUHTANIEMI I, PARVINEN M, VENHO P et al. - Combination of GnRH agonists with an antiandrogen or bromocriptine in the treatment of prostatic cancer: slight potentiation of antigonadal effects. Int J Androl 1991; 14:374-86.

34. HUHTANIEMI I, NIKULA H, RANNIKO S - Treatment of prostatic cancer with a gonadotropin-releasing hormone agonist analog: acute and long-term effects on endocrine functions of testis tissue. J Clin Endocrinol Metab 1985; 61: 698-704. 
35. DE KRETSER DM, HUIDOBRO C, SOUTHWICK GJ et al. - The role of the epididymis in human infertility. J Reprod Fertil 1998; 53:271-275.

36. COOPER TG, YEUNG C-H - Recent biochemical approaches to post-testicular, epididymal contraception. Human Reprod Update 1999; 5:141-152.

37. HAGAMAN JR, MOYER JS, BACHMAN ES et al. - Angiotensinconverting enzyme and male infertility. Proc Nat Acad Sci USA 1998; 95:2552-2557.

38. KJAERGAARD N, KJAERGAARD B, LAURIKEN JG - Prazosin, an adrenergic blocking agent inadequate as male contraceptive pill. Contraception 1988; 37:621-629.

39. YEUNG C-H, WAGENFELD A, NIESCHLAG E et al. - The cause of infertility of c-ros tyrosine kinase knockout male mice. Biol Reprod 2000; 63:612-618.

40. WALLACE EM, GOW SM, WU FCM - Comparison between testosterone enanthate induced azoospermia and oligospermia in a male contraceptive study. I Plasma luteinizing hormone, follicle stimulating hormone, testosterone, estradiol, and inhibin concentrations. J Clin Endocrinol Metab 1993; 77 : 290-3.

41. HDELSMAN DJ, FARLEY TMM, PERGOUDOV A et al. - Factors in nonuniform induction of azoospermia by testosterone enanthate in normal men. Fertil Steril 1995; 63:125-33.

42. ANDERSON RA, WU FCW - Comparison between testosterone enanthate-induced azoospermia and oligozoospermia in a male contraceptive study. II. Pharmacokinetics and pharmacodynamics of once weekly administration of testosterone enanthate. J Clin Endocrinol Metab 1996; 81:896-901.

43. ANDERSON RA,WU FCW - Comparison between testosterone enanthate-induced azoospermia and oligozoospermia in a male contraceptive study. III. Higher 5a-reductase activity in oligozoospermic men administered supraphysiological doses of testosterone. J Clin Endocrinol Metab 1996; 81:902-8.

44. WHO TASK FORCE ON METHODS FOR THE REGULATION OF MALE FERTILITY. - Rates of testosterone-induced suppression to severe oligozoospermia or azoospermia in two multinational clinical studies. Int J Androl 1995; 18:157-65.
45. WOLF CJ, HOTCHKISS A, OSTBY JS et al. - Effects of prenatal testosterone propionate on the sexual development of male and female rats: a dose-response study. Toxicol Sci 2002; 65: $71-86$.

46. WU FCW - Male contraception. Ballière's Clin Endocrinol Metab 1996; 10:1-23

47. BAGATELL CJ, HEIMAN JR, MATSUMOTO AM et al. Metabolic and behavioral effects of high-dose, exogenous testosterone in healthy men. J Clin Endocrinol Metab 1994; 79:561-7.

48. MERIGGIOLA MC, MARCOVINA S, PAULSEN CA et al. Testosterone enanthate at a dose of $200 \mathrm{mg} /$ week decreases HDL-cholesterol level in healthy men. Int J Androl 1995; 18: 237-42.

49. ANDERSON RA, WALLACE EM, FU FCW - Effect of testosterone enanthate on serum lipoproteins. Contraception $1985 ; \mathbf{5 2}: 115-19$

50. ANDERSON RA, LUDLAM CA, FU FCW - Haemostatic effects of supraphysiological levels of testosterone in normal men. Thromb Haemost 1995; 74:693-7.

51. WALLACE EM, PYE SD, WILD SR et al. - Prostate-specific antigen, and prostate size in men receiving exogenous testosterone for male contraception. Int J Androl 1993; 16: $35-40$.

52. ANDERSON RA, BANCROFT J, FU FCW - The effects of exogenous testosterone on sexuality mood of normal men. $\mathbf{J}$ Clin Endocrinol Metab 1992; 75:1503-7.

53. TRICKER R, CASABURI R, STORER TW et al. - The effects of supraphysiological doses of testosterone on angry behavior in healthy eugonadal men - a clinical research center study. J Clin Endocrinol Metab 1996; 81:3754-8.

54. HUHTANIEMI I. - Anabolic-androgenic steroids - a doubleedged sword? Int J Androl 1994; 17:57-62. 